\title{
Replacement of the descending thoracic aorta: Contemporary outcomes using hypothermic circulatory arrest
}

\author{
Alexander Kulik, MD, MPH, Catherine F. Castner, RN, and Nicholas T. Kouchoukos, MD
}

Objective: Recent advances in endovascular repair have put into question the role of open surgery on the descending thoracic aorta. We evaluated our experience with replacement of the descending thoracic aorta using hypothermic circulatory arrest.

\begin{abstract}
Methods: From May 1989 to August 2008, 151 patients (mean age $62 \pm 15$ years) had descending thoracic aorta replacement using cardiopulmonary bypass and hypothermic circulatory arrest. Concurrent distal aortic arch repair was performed in 71 patients $(47 \%)$. Seventeen patients $(11 \%)$ had emergency operation.
\end{abstract}

Results: The mean durations of bypass and circulatory arrest were $107 \pm 34$ and $32 \pm 9$ minutes, respectively. Stroke occurred in 5 patients $(3.3 \%)$, spinal cord ischemic injury in 2 patients $(1.3 \% ; 1$ paraplegia, 1 paraparesis), and renal failure requiring dialysis in 2 patients $(1.3 \%)$. Thirty-day and 6-month mortality rates were $4.0 \%$ and $9.9 \%$, respectively. Following emergency operation, the 30-day mortality rate was $17.6 \%$ compared with $2.2 \%$ after elective surgery $(P=.02)$. Five- and 10 -year survival rates were $71 \%$ and $45 \%$, respectively. Five patients required reoperation on the graft or contiguous aorta at a mean of $5 \pm 4$ years after the initial repair. Five- and 10 -year rates of freedom from reoperation were $96 \%$ and $92 \%$, respectively.

Conclusions: Cardiopulmonary bypass with hypothermic circulatory arrest can be safely used for replacement of the descending thoracic aorta. Although more invasive than endovascular stent grafting, this open surgical technique provides definitive repair, maintenance of left subclavian artery patency, protection against spinal cord injury, and early mortality and morbidity rates that do not exceed those reported for endovascular repair. (J Thorac Cardiovasc Surg 2010;139:249-55.)

Several open operative strategies exist for the management of disease involving the descending thoracic aorta (DTA), including the single-clamp technique, ${ }^{1}$ distal perfusion with left heart bypass, ${ }^{2}$ partial cardiopulmonary bypass (CPB), ${ }^{3}$ and hypothermic CPB with intervals of circulatory arrest. ${ }^{4}$ Recently, advances in endovascular repair of the DTA with stent grafts have put into question the role of open operation. Numerous series have been published confirming the feasibility of DTA stent grafting for the management of aortic aneurysms, penetrating ulcers, type $\mathrm{B}$ dissections, and traumatic transections. ${ }^{5-11}$ Because of its less invasive nature and relative ease of performance, there exists a perception that endovascular stent grafting of the DTA is associated with reduced morbidity and mortality, including a lower risk of spinal cord ischemic injury (SCII) and stroke, compared with open repair. ${ }^{8,12-14}$ Although stent-graft repair does eliminate the need for thoracic incisions and aortic

\footnotetext{
From the Division of Cardiovascular and Thoracic Surgery, Missouri Baptist Medical Center, St Louis, Mo.

Disclosures: None.

Oral Presentation during the Adult Cardiac Concurrent Forum at the 35th Annual Meeting of the Western Thoracic Surgical Association, Banff, Alberta, Canada, June 27, 2009.

Received for publication May 5, 2009; revisions received July 7, 2009; accepted for publication Aug 7, 2009; available ahead of print Dec 7, 2009.

Address for reprints: Nicholas T. Kouchoukos, MD, Cardiac, Thoracic and Vascular Surgery, 3009 North Ballas Road, Suite 360C, St Louis, MO 63131 (E-mail: ntkouch@aol.com).

0022-5223/\$36.00

Copyright (c) 2010 by American Association for Thoracic Surgery

doi:10.1016/j.jtcvs.2009.08.001
}

clamping, ${ }^{12,14}$ endovascular techniques are associated with important risks. Recent reports have documented morbidity and mortality rates ranging from $2 \%$ to $28 \% .^{10,15,16}$ Moreover, late complications have been reported, including endoleaks, graft migration, and aneurysm-related death. Secondary interventions are not infrequent. ${ }^{5,6}$ With a growing trend away from traditional surgical repair, we reviewed our contemporary experience with open DTA replacement using CPB with hypothermic circulatory arrest (HCA).

\section{METHODS}

\section{Patient Characteristics}

Between May 1989 and August 2008, 151 patients had DTA replacement with left thoracotomy, CPB, and HCA. The clinical characteristics of the patients are shown in Table 1 . The mean age at operation was $62 \pm 15$ years (range, 20-85), and 47 patients were women (31\%). Ten patients had clinical manifestations of Marfan syndrome (6.6\%). Eighty-three (55\%) had symptoms associated with their aortic disease. The remaining patients had aneurysms that were more than twice the size of adjacent normal aorta or had evidence of progressive aortic enlargement. Degenerative aneurysms were present in 92 patients $(61 \%)$. Twenty-five patients $(17 \%)$ had chronic type B dissections with aneurysm, and 7 patients $(4.6 \%)$ presented with complicated acute type B dissections. Seventeen patients $(11 \%)$ had emergency operation. Twenty-one patients $(14 \%)$ had previous operations on the DTA. The extent of the aortic disease requiring replacement is listed in Table 2. The study was reviewed by the Institutional Review Board of the Missouri Baptist Medical Center and was exempted from Board approval.

\section{Operative Technique}

Our general technique has been previously described. ${ }^{4}$ With increasing experience, several modifications have been introduced. Since September 


$$
\begin{aligned}
& \text { Abbreviations and Acronyms } \\
& \begin{aligned}
\text { CI } & =\text { confidence interval } \\
\text { CPB } & =\text { cardiopulmonary bypass } \\
\text { DTA } & =\text { descending thoracic aorta } \\
\text { HCA } & =\text { hypothermic circulatory arrest } \\
\text { OR } & =\text { odds ratio } \\
\text { SCII } & =\text { spinal cord ischemic injury }
\end{aligned}
\end{aligned}
$$

2004, cerebrospinal fluid drainage has been used in 12 patients who required extensive resection of the DTA. Following the insertion of monitoring catheters, the induction of anesthesia, and the placement of a double-lumen endotracheal tube, each patient was positioned in a right lateral decubitus position with the hips turned to the left at a $45^{\circ}$ angle. A posterolateral thoracotomy incision was made either in the fourth or fifth intercostal space. Simultaneously, the left common femoral artery and vein were isolated through an oblique incision in the skin crease of the groin. After heparin administration $(3 \mathrm{mg} / \mathrm{kg})$, a long cannula $(28 \mathrm{~F}-34 \mathrm{~F})$ was inserted through the left common femoral vein, and the tip was positioned in the right atrium under transesophageal echocardiographic guidance. The femoral artery was cannulated with an $18 \mathrm{~F}$ to $22 \mathrm{~F}$ short cannula. $\mathrm{CPB}$ was established, and cooling was initiated with a target nasopharyngeal temperature of $15^{\circ} \mathrm{C}$ to $17^{\circ} \mathrm{C}$. A catheter was placed through the left inferior pulmonary vein for venting of the left heart. Patients with significant aortic valve regurgitation (3-4+) required surgical intervention on the valve prior to having operation on the DTA.

In 1999, we modified our cannulation technique for 35 subsequently treated patients with atherosclerotic disease and degenerative aneurysms. In addition to standard femoral artery cannulation, a dispersion arterial cannula (Edwards Lifesciences Inc, Midvale, UT) was inserted directly into the DTA at a noncalcified thrombus-free site identified by epiaortic ultrasonography. The DTA cannula and the femoral cannula were then connected to separate arterial lines from the pump oxygenator. In these patients, CPB was established using the arterial line attached to the DTA cannula, and the femoral line was clamped. This technique was utilized to reduce the risk of retrograde embolization of thrombus or atheroma into the cerebral circulation. Alternatively, if cannulation of the DTA was inadvisable due to extensive atheromatous disease, a small left axillary incision was made, and an 8-mm collagen-impregnated graft was anastomosed to the left axillary artery to be used for proximal perfusion. The femoral arterial line remained clamped while the patient was cooled. In all other cases, including aortic dissection, the femoral artery was used to establish CPB. If a long period of HCA was anticipated during performance of the proximal anastomosis, a clamp was placed on the distal DTA, and low-flow perfusion was established to the lower body through the femoral arterial line for protection of the spinal cord, kidneys, and visceral organs.

During the period of cooling, methylprednisone $(7 \mathrm{mg} / \mathrm{kg})$ and thiopental ( 10 to $15 \mathrm{mg} / \mathrm{kg}$ ) were administered intravenously, and the head was packed in ice. The aorta proximal and distal to the diseased segment was isolated circumferentially. No cardioplegic solution was given, and no monitoring of somatosensory or motor evoked potentials was used. When electroencephalographic silence was achieved and the nasopharyngeal temperature was $22^{\circ} \mathrm{C}$ or less, circulatory arrest was established and the left heart vent was discontinued. The diseased segment of DTA was incised and, if indicated, the incision was extended into the aortic arch. The left phrenic, left vagus, and left recurrent nerves were identified and protected. A collagenimpregnated woven polyester aortic graft $(26-32 \mathrm{~mm})$ containing a 10 mm side arm (Hemashield; Meadox Medicals, Inc, Oakland, NJ) was sutured end-to-end to the transected proximal DTA or aortic arch with a continuous 3-0 or 4-0 polypropylene suture buttressed with a strip of felt. As this suture line was completed, cold blood $\left(10^{\circ} \mathrm{C}-12^{\circ} \mathrm{C}\right)$ from the pump ox-
TABLE 1. Preoperative patient characteristics $(n=151)$

\begin{tabular}{lc}
\hline \multicolumn{1}{c}{ Patient characteristic } & No. of patients (\%) \\
\hline Comorbidity & \\
Hypertension & $122(81 \%)$ \\
History of smoking & $75(50 \%)$ \\
Hyperlipidemia & $69(46 \%)$ \\
Chronic obstructive pulmonary disease & $15(10 \%)$ \\
Coronary artery disease & $55(36 \%)$ \\
Peripheral vascular disease & $37(25 \%)$ \\
Creatinine $\geq 1.5$ mg/dL & $19(13 \%)$ \\
Previous transient ischemic attack or stroke & $16(11 \%)$ \\
Marfan syndrome & $10(6.6 \%)$ \\
Diabetes mellitus & $6(4.0 \%)$ \\
Previous operations & \\
Coronary artery bypass grafting or & $40(26 \%)$ \\
$\quad$ percutaneous coronary intervention & \\
Aortic valve procedure & $30(20 \%)$ \\
Ascending aortic repair & $25(17 \%)$ \\
Aortic arch repair & $11(7.3 \%)$ \\
Descending thoracic aortic repair & $21(14 \%)$ \\
Abdominal aortic aneurysm repair & $28(19 \%)$ \\
Etiology of aortic disease & \\
Degenerative aneurysm & $92(61 \%)$ \\
Chronic type B dissection & $25(17 \%)$ \\
Acute type B dissection & $7(4.6 \%)$ \\
Aortic coarctation & $11(7.3 \%)$ \\
Other & $16(11 \%)$ \\
\hline
\end{tabular}

ygenator was infused retrogradely into the venous cannula to assist in the evacuation of air and debris from the heart, upper circulation, and graft (flow rate up to $800 \mathrm{~mL} / \mathrm{min}$, maximum central venous pressure $20 \mathrm{~mm}$ $\mathrm{Hg}$ ). The side arm of the graft was attached to the proximal arterial line from the pump oxygenator. After evacuation of air, a clamp was placed on the graft just distal to the side arm, and flow to the upper body was reestablished at a rate of 15 to $20 \mathrm{~mL} / \mathrm{kg} / \mathrm{min}$ and a temperature of $20^{\circ} \mathrm{C}$ to $22^{\circ} \mathrm{C}$. This minimized the interval of circulatory arrest and reestablished circulation to the brain, vertebral arteries, and upper extremities.

Distally, the aorta was transected below the diseased segment, and the distal anastomosis was performed with a continuous $3-0$ or 4-0 polypropylene suture buttressed with a strip of felt. If technically feasible, this anastomosis was performed with the distal DTA occluded while low-flow lower-body perfusion was continued through the femoral arterial line. If not feasible, the distal aortic clamp was removed after discontinuing flow, and an open anastamosis was performed. As the distal suture line was being completed, perfusion through the femoral arterial line was used to evacuate air and debris. Additional air was evacuated from the graft through multiple puncture sites created with an $18 \mathrm{G}$ needle. Flow from the femoral arterial line was discontinued, the proximal clamp was removed, and full antegrade flow was established from the proximal arterial line. Rewarming was then initiated. Spontaneous defibrillation usually occurred when the nasopharyngeal temperature reached $26^{\circ} \mathrm{C}$ to $28^{\circ} \mathrm{C}$. When the bladder temperature reached $35^{\circ} \mathrm{C}$, the pulmonary vein venting catheter was removed and $\mathrm{CPB}$ was discontinued.

Whenever the distal DTA was replaced, an attempt was made to reimplant patent intercostal arteries. Patent arteries below the level of the sixth or seventh intercostal space were reimplanted when technically feasible, assuming the aortic tissue surrounding the arteries was of adequate quality. This was accomplished in $22(34 \%)$ of the 65 patients who had distal DTA replacement. If possible, the clamp on the aortic graft was repositioned below the intercostal artery-to-graft anastomosis before the distal 
TABLE 2. Extent of aortic repair

\begin{tabular}{lc}
\hline Extent of repair & No. of patients \\
\hline Proximal DTA & \\
With distal arch & 58 \\
Without distal arch & 28 \\
Entire DTA & \\
With distal arch & 13 \\
Without distal arch & 35 \\
Distal DTA & 17 \\
Total & 151 \\
\hline
\end{tabular}

anastomosis was performed to permit early perfusion of the implanted intercostal arteries. In 10 patients $(7 \%)$, continuity of the left subclavian artery was maintained with an 8 - to 10 -mm collagen-impregnated graft inserted between the aortic graft and the subclavian artery.

A membrane oxygenator (Optima XP; Cobe Cardiovascular, Arvada, Colo) was used in all cases. The mean durations of cooling, circulatory arrest, low-flow hypothermic bypass, hypothermic ventricular fibrillation, rewarming, and CPB are shown in Table 3 . The mean duration of circulatory arrest was $31.7 \pm 9.4$ minutes. A period of hypothermic low flow to the upper body after attachment of the aortic graft to the proximal aorta was used in 86 patients (mean duration, $25.4 \pm 14.3$ minutes) to minimize the interval of circulatory arrest.

\section{Follow-up}

After hospital discharge, patients were evaluated at 1 and 6 months postoperatively and subsequently at 12-month intervals. Computed tomography scans were obtained prior to discharge, at 6 months, and yearly thereafter. Follow-up was $100 \%$ complete. Mean duration of follow-up was 4 years (range, 1 month to 18 years).

\section{Statistical Analyses}

Data were analyzed in Intercooled Stata 9.2 (Stata, College Station, Tex). Standard descriptive statistical analyses were used. Continuous data, presented as a mean \pm standard deviation, were compared between groups using unpaired 2 -sided Student $t$ tests. Categorical data, presented as proportions, were compared between groups using Fisher exact test. Nonparametric estimates of freedom from all-cause death and reoperation were determined using the Kaplan-Meier method. A composite outcome was developed that incorporated the adverse perioperative events of 30-day mortality, SCII, stroke, and need for dialysis. Predictors of adverse perioperative events were determined with multivariate logistic regression. Multivariate models were developed by incorporating variables that had

TABLE 3. Cardiopulmonary perfusion data

\begin{tabular}{lcc}
\hline & Mean \pm SD & Range \\
\hline Time (min) & & \\
$\quad$ Cardiopulmonary bypass & $107.2 \pm 33.9$ & $57-346$ \\
Cooling & $32.2 \pm 8.7$ & $18-61$ \\
Circulatory arrest & $31.7 \pm 9.4$ & $11-53$ \\
Low-flow hypothermic bypass* & $25.4 \pm 14.3$ & $5-81$ \\
Hypothermic ventricular fibrillation & $76.8 \pm 21.1$ & $30-140$ \\
$\quad$ Rewarming & $57.7 \pm 13.0$ & $30-115$ \\
Temperature $\left({ }^{\circ} \mathrm{C}\right)$ & & \\
$\quad$ Lowest nasopharyngeal & $15.4 \pm 2.1$ & $11-22$ \\
$\quad$ Lowest bladder/rectal & $20.0 \pm 3.1$ & $13-28$ \\
\hline
\end{tabular}

$S D$, Standard deviation. *Eighty-six patients.
TABLE 4. Extent of repair and associated morbidity and mortality

\begin{tabular}{|c|c|c|c|c|}
\hline Extent of repair & $\begin{array}{c}\text { 30-d } \\
\text { mortality }\end{array}$ & Stroke & $\begin{array}{c}\text { Spinal cord } \\
\text { ischemic injury }\end{array}$ & Dialysis \\
\hline \multicolumn{5}{|l|}{ Proximal DTA } \\
\hline $\begin{array}{l}\text { With distal arch } \\
\qquad(\mathrm{n}=58)\end{array}$ & 1 & 4 & 0 & 1 \\
\hline $\begin{array}{l}\text { Without distal arch } \\
\qquad(\mathrm{n}=28)\end{array}$ & 0 & 1 & 0 & 0 \\
\hline \multicolumn{5}{|l|}{ Entire DTA } \\
\hline With distal $\operatorname{arch}(\mathrm{n}=13)$ & 1 & 0 & 1 & 0 \\
\hline $\begin{array}{l}\text { Without distal arch } \\
\quad(\mathrm{n}=35)\end{array}$ & 3 & 0 & 1 & 1 \\
\hline Distal DTA $(\mathrm{n}=17)$ & 1 & 0 & 0 & 0 \\
\hline Total $(n=151)$ & $6(4.0 \%)$ & $5(3.3 \%)$ & $2(1.3 \%)$ & $2(1.3 \%)$ \\
\hline
\end{tabular}

DTA, Descending thoracic aorta.

a $P$ value of .20 or less on univariate testing. Stepwise forward selection and backward elimination techniques were employed with $P=.20$ for entry and removal criteria. Odds ratios (ORs) are reported with $95 \%$ confidence intervals (CIs).

\section{RESULTS}

\section{Early Mortality}

The 30-day mortality rate for the entire group was $4.0 \%$ (6 patients). The mortality according to the extent of aorta replaced is summarized in Table 4. In patients who had previous operation on the DTA, the 30-day mortality was $9.5 \%$, compared with $3.1 \%$ in those who had not $(P=.20)$. Following emergent operation, the 30-day mortality rate was $17.6 \%$ compared with $2.2 \%$ after elective surgery $(P=.02)$. Among patients treated as emergencies, 1 patient died intraoperatively due to myocardial failure during a repair of a ruptured chronically dissected aorta. She had previously had open repair and stent-graft repair of the DTA, and she was known preoperatively to have left ventricular dysfunction. One patient died from right ventricular failure 2 days after an emergency repair of a ruptured aneurysm, and another died from cardiac arrest 20 days after emergency repair of a ruptured aneurysm. The latter patient's postoperative course was complicated by deep vein thrombosis and renal failure requiring dialysis. After elective surgery, 1 patient died from a cardiac arrest 9 days following an aneurysm repair, 1 died 23 days after operation from a stroke that developed 12 days postoperatively, and 1 died 26 days after aneurysm repair from severe chronic obstructive pulmonary disease and respiratory failure. Two additional patients died during the hospital stay from complications of sepsis, 46 days after an elective reoperation and 93 days after an emergency operation. Three other patients died within 6 months of surgery (causes: sepsis, cardiac arrest, and cardiac tamponade). The 6-month mortality rate was $9.9 \%$.

\section{Neurologic Complications}

SCII occurred in 2 patients $(1.3 \%)$, both prior to the routine use of cerebrospinal fluid drainage. Neurologic injury 
TABLE 5. Postoperative morbidity $(n=151)$

\begin{tabular}{lc}
\hline \multicolumn{1}{c}{ Type of morbidity } & No. of patients (\%) \\
\hline Exploration for bleeding & $6(4.0 \%)$ \\
Low cardiac output (inotropes $>48 \mathrm{~h})$ & $3(2.0 \%)$ \\
Renal dysfunction requiring dialysis & $2(1.3 \%)$ \\
Gastrointestinal bleeding or ischemia & $9(6.0 \%)$ \\
Deep vein thrombosis or pulmonary embolus & $9(6.0 \%)$ \\
Pneumonia & $33(22 \%)$ \\
Wound infections & $4(2.6 \%)$ \\
Sepsis & $4(2.6 \%)$ \\
\hline
\end{tabular}

according to the extent of aorta replacement is listed in Table 4. Paraplegia developed after replacement of the entire DTA in 1 patient who had previously had repair of an infrarenal abdominal aortic aneurysm 1 year earlier. During his DTA operation, intercostal arteries at $\mathrm{T} 6, \mathrm{~T} 8$, and $\mathrm{T} 10$ were judged not to be implantable and were oversewn. When the neurologic injury became apparent on postoperative day 1, a spinal drain was inserted, but no neurologic recovery occurred. Another patient developed paraparesis after replacement of the entire DTA and distal aortic arch. During her DTA operation, intercostal arteries at T7, T8, and T10 were oversewn, and no other intercostals were reimplantable. Her neurologic function returned completely.

Five patients $(3 \%)$ had a stroke. Four of these patients had stroke prior to the routine use of proximal perfusion through a DTA cannula. Among the 92 patients with degenerative atherosclerotic aneurysms, the stroke rate was $2.9 \%$ (1 out of 35) with the use of DTA cannulation, compared with $5.3 \%$ (3 out of 57) with the sole use of femoral artery cannulation. Bilateral cerebellar infarcts developed in the patient who had a stroke using the contemporary strategy of DTA cannulation, likely from embolization of extensive atheromatous material found in the aorta adjacent to the origin of the left subclavian artery.

\section{Other Morbidity}

Intraoperative transfusion of blood products was required in 121 patients $(80 \%)$. Average intraoperative transfusion requirements were $5.0 \pm 3.6 \mathrm{U}$ (median, $4 \mathrm{U}$ ) of packed red blood cells, $4.2 \pm 2.6 \mathrm{U}$ (median, $4 \mathrm{U}$ ) of fresh frozen plasma, and $2.8 \pm 2.0 \mathrm{U}$ (median, $2 \mathrm{U}$ ) of platelets. Ventilatory support was required for a mean of $3 \pm 10$ days (median, 1 day), and 8 patients $(5 \%)$ required temporary tracheostomy. The duration of intensive care unit stay was $6 \pm 9$ days (median, 4 days). Hospital length of stay was $16 \pm 15$ days (median, 11 days). Additional morbidity data are listed in Table 5.

The composite outcome (incorporating 30-day mortality, SCII, stroke, and need for dialysis) occurred in 13 patients $(9 \%)$. Predictors associated with the composite outcome on univariate analysis included older age (OR: 1.1 per each additional year; $95 \% \mathrm{CI}: 1.0,1.2 ; P=.01)$, increasing

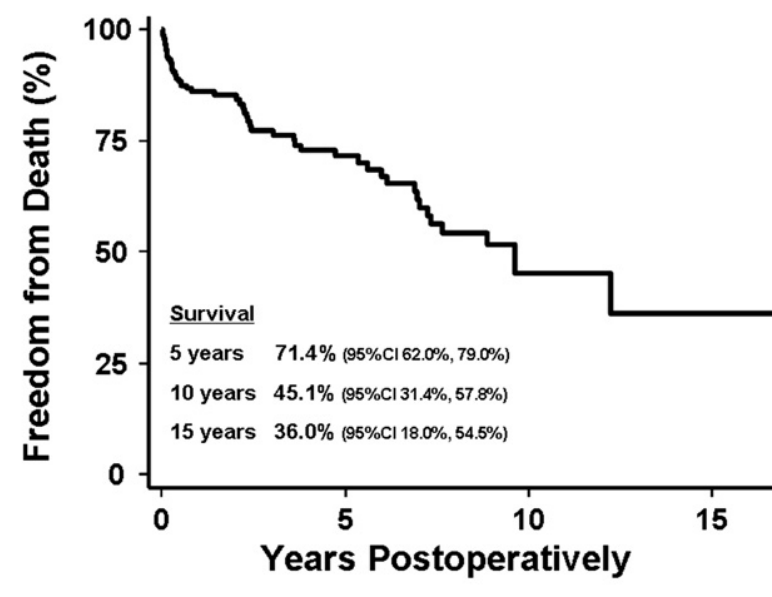

Patients at Risk 151 55 14 4

FIGURE 1. Long-term survival after descending thoracic aorta repair among the entire cohort. $C I$, Confidence interval.

duration of CPB (OR: 1.1 per each additional 10 minutes; $95 \% \mathrm{CI}: 1.0,1.3 ; P=.05$ ), previous abdominal aortic aneurysm repair (OR: $2.7 ; 95 \%$ CI: $0.7,9.7 ; P=.13$ ), the presence of coronary artery disease (OR: $3.1 ; 95 \%$ CI: $0.9,9.9$; $P=.06$ ), the presence of peripheral vascular disease (OR: $2.9 ; 95 \%$ CI: $0.9,9.3 ; P=.07)$, and the need for emergency surgery (OR: $6.6 ; 95 \%$ CI: 1.9, 23.2; $P=.004$ ). On multivariate logistic regression, independent predictors of the composite outcome were the need for emergency surgery (adjusted OR: 11.8; 95\% CI: 2.1, 66.6; $P=.005$ ), and older age (adjusted OR: 1.1 per each additional year; $95 \% \mathrm{CI}: 1.0$, $1.2 ; P=.02)$.

\section{Long-term Follow-up}

During the follow-up period that extended to 18 years, there were 35 late deaths. Five- and 10-year survival rates were $71 \%$ and $45 \%$, respectively (Figure 1). Patients with degenerative aneurysms had 5- and 10-year survival rates of $66 \%$ and $32 \%$, compared with $80 \%$ and $75 \%$ among all other patients $(P=.003$; Figure 2$)$. Five patients needed reoperation on the graft or contiguous aorta at a mean of $5 \pm$ 4 years after the initial procedure. Indications for reoperation included a bleeding intercostal patch 3 weeks postoperatively (1), late aneurysmal dilatation of the intercostal patch (2), or progressive dilatation of the proximal (1), or distal DTA (1). Five- and 10-year actuarial rates of freedom from reoperation were $96 \%$ and 92\%, respectively (Figure 3). The remaining patients are free of symptoms and abnormal findings of the contiguous aorta on serial computed tomography examinations from 1 month to 18 years postoperatively.

\section{DISCUSSION}

The optimal open surgical technique for the management of disease involving the DTA has yet to be established. A number of operative strategies exist, including the 


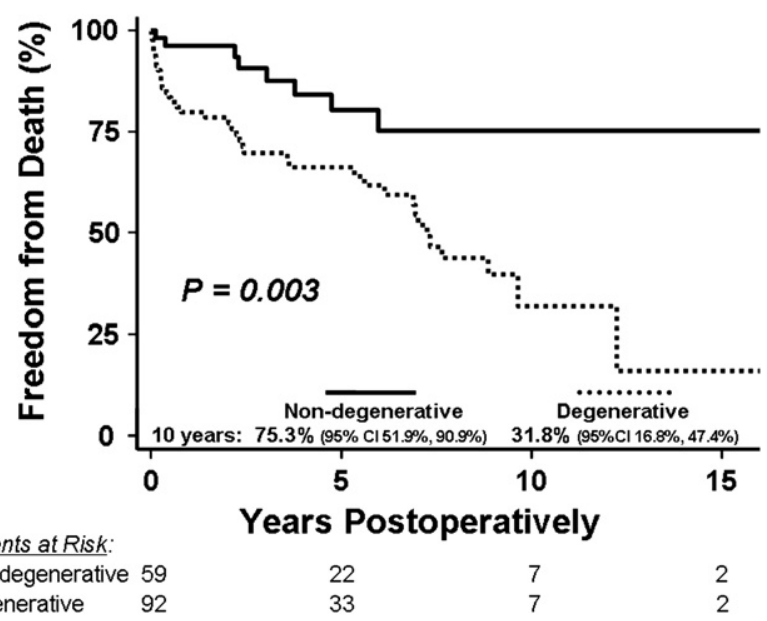

Non-degenerative 59

FIGURE 2. Long-term survival after descending thoracic aorta repair among patients treated for degenerative or nondegenerative aneurysms. Long-term survival was significantly better in patients with nondegenerative aneurysms. $C I$, Confidence interval.

single-clamp technique, ${ }^{1}$ distal perfusion with left heart bypass, ${ }^{2}$ and partial CPB. ${ }^{3}$ Hypothermic CPB with intervals of circulatory arrest has proven to be a safe and effective means for protection of the central nervous system during complex cardiac surgery. Applying this technique to the repair of the DTA provides a bloodless field and access to the aortic arch, as well as eliminating the need for proximal and sequential aortic clamping, extensive mobilization of the aorta, and monitoring of evoked potentials. The majority of the shed blood is returned to the perfusion circuit, and excellent protection of the central nervous system, the heart, and the viscera is provided by hypothermia. Through the process of metabolic down-regulation, HCA increases ischemic tolerance and allows for an unhurried aortic reconstruction in

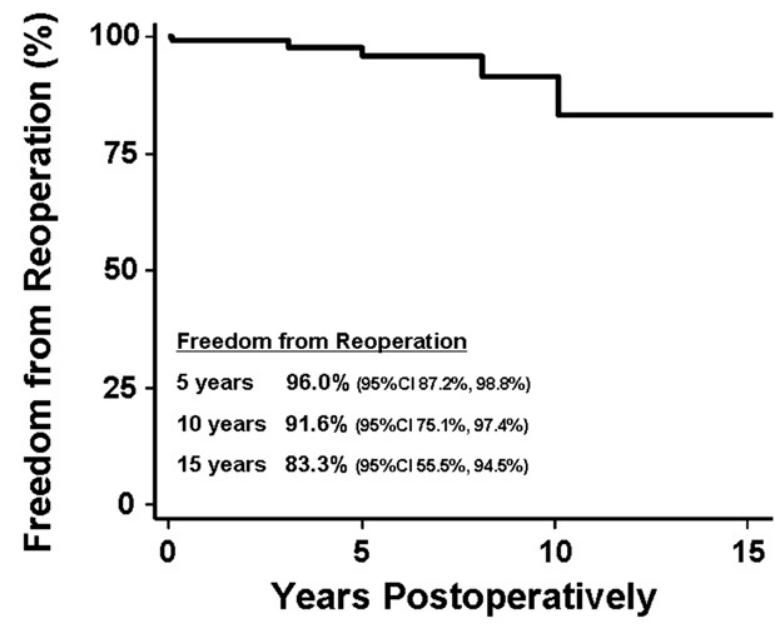

Patients at Risk 151 52 12 3

FIGURE 3. Freedom from reoperation on the graft or contiguous aorta after descending thoracic aorta repair. $C I$, Confidence interval. addition to the identification and reimplantation of intercostal arteries.

First described in $1994,{ }^{17}$ stent-graft repair has gradually gained favor as a treatment option for DTA pathology. Although initially applied for degenerative aneurysms of the DTA, endovascular techniques are increasingly being used in the management of traumatic transections, acute and chronic dissections, and penetrating ulcers. Recently, aneurysms of the aortic arch and thoracoabdominal aorta have been treated with investigational hybrid and debranching endovascular techniques. These advances have put into question the role of open DTA surgery in the modern era. Arguments in favor of these novel endovascular therapies often refer to high morbidity and mortality rates reported in surgical series published more than 20 years ago. ${ }^{11,17,18}$

With a growing movement away from open surgical repair, the goal of the current study was to present contemporary surgical outcomes using $\mathrm{CPB}$ and HCA during repair of the DTA. Our results illustrate that, when applied on a routine basis, DTA repair using HCA is a safe and durable procedure. Adverse neurologic events occurred infrequently, with SCII and stroke occurring in $1.3 \%$ and $3.3 \%$ of patients, respectively. Thirty-day mortality was $4.0 \%$, driven mostly by the $17.6 \%$ mortality rate among patients treated as emergencies. In contrast, elective repair was associated with a 30-day mortality of $2.2 \%$, a stroke rate of $3.0 \%$, and SCII rate of $1.5 \%$. Independent risk factors associated with adverse perioperative events included the need for emergency surgery and older age. Five patients required reoperation on the graft or contiguous aorta at a mean of $5 \pm 4$ years after the initial repair, and the 10-year rate of freedom from reoperation was $92 \%$. In our view, these results compare favorably with those currently reported for endovascular repair ${ }^{5-12,15,16,19}$ and confirm that $\mathrm{CPB}$ with $\mathrm{HCA}$ is a reliable and effective technique for repair of the DTA.

Hypothermia is a valuable adjunct for the treatment of complex aortic disease and has been shown to reduce the incidence of postoperative neurologic deficits. ${ }^{20}$ Early in our experience, we selectively applied CPB with HCA in the presence of extensive descending aortic disease involving the distal aortic arch, when the risk of paraplegia was judged to be increased, or when we felt that clamping of the proximal aorta was unsafe due to severe atherosclerosis. Over time, however, we have used $\mathrm{CPB}$ with HCA on a routine basis for all patients with extensive aneurysms and dissections of the DTA and in patients with thoracoabdominal aortic aneurysms. ${ }^{4}$ Hypothermia remains the most effective intervention for protecting neural tissue against ischemic injury.

The results reported herein add to other contemporary series involving open surgical repair of the DTA. Using the classic clamp-and-sew technique in 132 patients, Cooley and colleagues ${ }^{1}$ reported a 30 -day mortality rate of $12.9 \%$ and SCII rate of $8.3 \%$. In comparison, results have generally 
TABLE 6. Contemporary risks associated with endovascular stent-graft repair of the descending thoracic aorta

\begin{tabular}{|c|c|c|c|c|c|}
\hline Authors & No. of patients & 30-d mortality $(\%)$ & Spinal cord ischemic injury $(\%)$ & Stroke $(\%)$ & Renal failure requiring dialysis $(\%)$ \\
\hline Patel et $\mathrm{al}^{5}$ & 73 & 5.5 & 4.1 & 8.2 & 4.1 \\
\hline Hughes et $\mathrm{al}^{7}$ & 83 & 3.6 & 6.0 & 3.6 & - \\
\hline Stone et $\mathrm{al}^{6}$ & 105 & 6.7 & 6.7 & 9.5 & - \\
\hline Brown et $\mathrm{al}^{8}$ & 116 & 5.2 & 2.6 & 8.6 & 2.6 \\
\hline Bavaria et $\mathrm{al}^{19}$ & 140 & 2.1 & 2.9 & 3.6 & 1.4 \\
\hline Makaroun et al ${ }^{10}$ & 142 & 1.5 & 2.8 & 3.5 & - \\
\hline Wheatley et $\mathrm{al}^{9}$ & 158 & 3.8 & 2.5 & 2.5 & 2.5 \\
\hline Greenberg et $\mathrm{al}^{12}$ & 163 & 4.9 & 0.6 & - & - \\
\hline Leurs et al ${ }^{15}$ & 443 & 9.3 & 2.5 & 2.2 & - \\
\hline Fattori et al ${ }^{16}$ & 457 & 5.0 & 1.8 & 3.7 & 0.9 \\
\hline Buth et al ${ }^{11}$ & 606 & 9.9 & 2.5 & 3.1 & - \\
\hline
\end{tabular}

been better in series where neuroprotective adjuncts have been applied, including distal aortic perfusion and cerebrospinal fluid drainage. In a series of 300 elective patients with DTA aneurysms, Estrera and associates ${ }^{2}$ reported a 30 -day mortality rate of $8 \%$ and SCII in $2.3 \%$ of patients. The incidence of neurologic deficits was lower in those patients who had repair with both left heart bypass and cerebrospinal fluid drainage compared with those who did not $(1.3 \%$ vs $6.5 \%, P<.02)$. Minatoya and coworkers ${ }^{21}$ recently reported their experience using partial CPB to replace the DTA in 112 patients. The early mortality rate was $5.3 \%$. Similar to our experience, their elective mortality rate $(1.0 \%)$ was much lower compared with emergency cases $(31.3 \%)$. The stroke rate was $7.1 \%$, and SCII occurred in $2.7 \%$. Applying the technique of CPB with HCA for DTA repair in 132 patients, Patel and colleagues ${ }^{22}$ documented a 30-day mortality of $6.0 \%$, SCII $4.5 \%$, and dialysis-dependent renal failure in $5.3 \%$. The incidence of stroke, $6.8 \%$, was somewhat higher compared with our experience, possibly related to their exclusive use of femoral artery cannulation. Cannulation of the DTA or the left axillary artery may lower the risk of retrograde embolization and stroke, particularly in patients with degenerative aneurysms. Although concerns have been raised regarding excessive bleeding and respiratory complications with HCA, our results compare favorably to those reported from centers applying alternative surgical techniques. ${ }^{1-3,21,22}$

Endovascular stent-graft repair is an attractive option for the treatment of DTA disease. Endovascular repair features incisions limited to the groin, minimal organ ischemia, less blood loss and fluid shifts, and a lower stress on the cardiopulmonary system. ${ }^{12}$ Optimism for stent-graft repair was generated from the report of the initial Gore TAG trial that led to the US Food and Drug Administration approval. A carefully selected group of patients with degenerative aneurysms were recruited into the stent-graft arm of the study based on strict inclusion and exclusion criteria. For comparison, a surgical group enrolled historical and concurrent subjects treated with a variety of different operative techniques. Favorable outcomes were reported with the Gore TAG graft, including 30-day rates of death, stroke, and SCII of $2.1 \%$, $3.6 \%$, and $2.9 \%$, respectively. ${ }^{19}$ With encouraging early stent-graft results, a claim has consistently been made in the literature that, compared with conventional open repair, stent grafting of the DTA is associated with reduced morbidity and mortality, including a lower risk of SCII and stroke. ${ }^{8,12-14}$

Although no randomized trials exist, more recent stentgraft series have documented morbidity and mortality rates that do not differ substantially from those with open repair (Table 6). The European Collaborators on Stent/Graft Techniques for Aortic Aneurysm Repair (EUROSTAR) database recently reported outcomes involving 606 patients treated with DTA endovascular repair. The 30-day mortality was $9.9 \%$, SCII developed in $2.5 \%$, and stroke occurred in $3.1 \%,{ }^{11}$ results that are comparable to those reported in the current study. A recent systematic review compared DTA outcomes from the 5 largest series of open surgical repair (1716 cases) to pooled data from the 17 largest series of endovascular stent-graft repair (1342 cases). ${ }^{23}$ Outcomes were nearly identical for open surgery compared with stent-graft repair (operative mortality rate: $4.8 \%$ vs $6.3 \%$, open vs stent, $P=.51$; paraplegia: $2.9 \%$ vs $1.4 \%$, open vs stent, $P=.11$; stroke: $3.2 \%$ vs $2.4 \%$, open vs stent, $P=.52$ ). Importantly, late complication rates have not been infrequent in published series, including endoleaks, graft migration, need for open operation, and aneurysmrelated death. During short follow-up intervals, secondary interventions have been required in $6 \%$ to $12 \%$ of patients. ${ }^{5-11}$ Long-term performance remains unknown.

In general, we favor open surgical repair for the treatment of DTA pathology, particularly in patients at low operative risk, those with connective tissue disorders or chronic aortic dissections, and in younger patients who may benefit from the excellent long-term durability and low reintervention rate associated with open repair. However, we acknowledge that stent-graft repair has an important role in the management of select patients with DTA disease. Elderly patients and those with severe comorbidities, including poor cardiac and pulmonary reserve, appear to be ideal candidates for this 
less invasive procedure, keeping in mind the poor long-term survival of patients who are unsuitable for conventional open surgical repair. ${ }^{24}$ Since August 2005, we have performed stent-graft repair in 16 patients with DTA disease. We have restricted stent-graft implantation to patients with either degenerative aneurysms or penetrating ulcers that have adequate anatomic landing zones. Patients with suture line pseudoaneurysms or intercostal patch aneurysms following previous open aortic repair are also suitable candidates, ${ }^{25}$ if the anatomy is favorable for stent-graft exclusion.

\section{Limitations}

This study is the largest to date to report outcomes associated with DTA repair using CPB with HCA. However, the results presented must be interpreted within the context of the study design. Observational in nature, this study involved the retrospective review of prospectively collected data in a referral-based tertiary care center. Surgical techniques evolved during the 20-year period of the study. Although many patients were referred from afar, every effort was made to obtain imaging surveillance at regular intervals, even if from a distance. Patient outcomes were documented by direct examination or through communication with family members or referring physicians.

\section{CONCLUSIONS}

In summary, we have documented that CPB with HCA can be safely used in the replacement of the DTA and the distal aortic arch when necessary. Although more invasive than endovascular stent-graft placement, this open surgical technique provides definitive repair, maintenance of left subclavian artery patency, a low incidence of reoperation, and early mortality and morbidity rates that do not exceed those reported for endovascular repair.

\section{References}

1. Cooley DA, Golino A, Frazier OH. Single-clamp technique for aneurysms of the descending thoracic aorta: report of 132 consecutive cases. Eur J Cardiothorac Surg. 2000;18:162-7.

2. Estrera AL, Miller CC 3rd, Chen EP, Meada R, Torres RH, Porat EE, et al. Descending thoracic aortic aneurysm repair: 12-year experience using distal aortic perfusion and cerebrospinal fluid drainage. Ann Thorac Surg. 2005;80:1290-6; discussion 1296.

3. Coady MA, Mitchell RS. Femoro-femoral partial bypass in the treatment of thoracoabdominal aneurysms. Semin Thorac Cardiovasc Surg. 2003;15:340-4

4. Kouchoukos NT, Masetti P, Rokkas CK, Murphy SF, Blackstone EH. Safety and efficacy of hypothermic cardiopulmonary bypass and circulatory arrest for operations on the descending thoracic and thoracoabdominal aorta. Ann Thorac Surg. 2001;72:699-707; discussion 707-8.

5. Patel HJ, Williams DM, Upchurch GR Jr, Shillingford MS, Dasika NL, Proctor MC, et al. Long-term results from a 12-year experience with endovascular therapy for thoracic aortic disease. Ann Thorac Surg. 2006;82:2147-53.
6. Stone DH, Brewster DC, Kwolek CJ, Lamuraglia GM, Conrad MF, Chung TK, et al. Stent-graft versus open-surgical repair of the thoracic aorta: mid-term results. J Vasc Surg. 2006;44:1188-97.

7. Hughes GC, Daneshmand MA, Swaminathan M, Nienaber JJ, Bush EL, Husain $\mathrm{AH}$, et al. Real world' thoracic endografting: results with the Gore TAG device 2 years after U.S. FDA approval. Ann Thorac Surg. 2008;86: 1530-7; discussion 1537-38.

8. Brown KE, Eskandari MK, Matsumura JS, Rodriguez H, Morasch MD. Short and midterm results with minimally invasive endovascular repair of acute and chronic thoracic aortic pathology. J Vasc Surg. 2008;47:714-22; discussion 722-3.

9. Wheatley GH 3rd, Gurbuz AT, Rodriguez-Lopez JA, Ramaiah VG, Olsen D, Williams J, et al. Midterm outcome in 158 consecutive Gore TAG thoracic endoprostheses: single center experience. Ann Thorac Surg. 2006;81:1570-7; discussion 1577 .

10. Makaroun MS, Dillavou ED, Kee ST, Sicard G, Chaikof E, Bavaria J, et al. Endovascular treatment of thoracic aortic aneurysms: results of the phase II multicenter trial of the GORE TAG thoracic endoprosthesis. J Vasc Surg. 2005;41:1-9.

11. Buth J, Harris PL, Hobo R, van Eps R, Cuypers P, Duijm L, et al. Neurologic complications associated with endovascular repair of thoracic aortic pathology: incidence and risk factors. a study from the European Collaborators on Stent/Graft Techniques for Aortic Aneurysm Repair (EUROSTAR) registry. J Vasc Surg. 2007;46:1103-10; discussion 1110-1.

12. Greenberg RK, Lu Q, Roselli EE, Svensson LG, Moon MC, Hernandez AV, et al Contemporary analysis of descending thoracic and thoracoabdominal aneurysm repair: a comparison of endovascular and open techniques. Circulation. 2008; 118:808-17.

13. Nienaber CA, Kische S, Ince H. Thoracic aortic stent-graft devices: problems, failure modes, and applicability. Semin Vasc Surg. 2007;20:81-9.

14. Gravereaux EC, Faries PL, Burks JA, Latessa V, Spielvogel D, Hollier LH, et al. Risk of spinal cord ischemia after endograft repair of thoracic aortic aneurysms. J Vasc Surg. 2001;34:997-1003.

15. Leurs LJ, Bell R, Degrieck Y, Thomas S, Hobo R, Lundbom J. Endovascular treatment of thoracic aortic diseases: combined experience from the EUROSTAR and United Kingdom Thoracic Endograft registries. J Vasc Surg. 2004;40:670-9; discussion 679-80.

16. Fattori R, Nienaber CA, Rousseau H, Beregi JP, Heijmen R, Grabenwoger M, et al. Results of endovascular repair of the thoracic aorta with the Talent Thoracic stent graft: the Talent Thoracic Retrospective Registry. J Thorac Cardiovasc Surg. 2006;132:332-9.

17. Dake MD, Miller DC, Semba CP, Mitchell RS, Walker PJ, Liddell RP. Transluminal placement of endovascular stent-grafts for the treatment of descending thoracic aortic aneurysms. N Engl J Med. 1994;331:1729-34.

18. Katzen BT, Dake MD, MacLean AA, Wang DS. Endovascular repair of abdominal and thoracic aortic aneurysms. Circulation. 2005;112:1663-75.

19. Bavaria JE, Appoo JJ, Makaroun MS, Verter J, Yu ZF, Mitchell RS. Endovascular stent grafting versus open surgical repair of descending thoracic aortic aneurysms in low-risk patients: a multicenter comparative trial. $J$ Thorac Cardiovasc Surg. 2007; 133:369-77.

20. Svensson LG, Khitin L, Nadolny EM, Kimmel WA. Systemic temperature and paralysis after thoracoabdominal and descending aortic operations. Arch Surg. 2003; 138:175-9; discussion 180.

21. Minatoya K, Ogino H, Matsuda H, Sasaki H, Yagihara T, Kitamura S. Replacement of the descending aorta: recent outcomes of open surgery performed with partial cardiopulmonary bypass. J Thorac Cardiovasc Surg. 2008;136:431-5.

22. Patel HJ, Shillingford MS, Mihalik S, Proctor MC, Deeb GM. Resection of the descending thoracic aorta: outcomes after use of hypothermic circulatory arrest. Ann Thorac Surg. 2006;82:90-5; discussion 95-6.

23. Gleason TG, Benjamin LC. Conventional open repair of descending thoracic aortic aneurysms. Perspect Vasc Surg Endovasc Ther. 2007;19:110-21.

24. Demers P, Miller DC, Mitchell RS, Kee ST, Sze D, Razavi MK, et al. Midterm results of endovascular repair of descending thoracic aortic aneurysms with first-generation stent grafts. J Thorac Cardiovasc Surg. 2004;127:664-73.

25. Kulik A, Allen BT, Kouchoukos NT. Incidence and management of intercostal patch aneurysms after repair of thoraco-abdominal aortic aneurysms. $J$ Thorac Cardiovasc Surg. 2009 (in press). 